\title{
Immediate food hypersensitivity reactions on the first known exposure to the food
}

\author{
P P VAN ASPEREN, A S KEMP, AND C M MELLIS
}

Department of Immunology and Department of Respiratory Medicine, Royal Alexandra Hospital for Children, Camperdown, New South Wales, Australia

SUMMARY We report 8 infants with immediate hypersensitivity reactions to foods (milk, egg, or peanut), occurring at the first-known exposure. Each developed symptoms within the first hour, but these generally settled within 2 hours. Sensitisation to the food concerned was demonstrated by positive immediate allergen skin prick tests in every case. Symptoms experienced included irritability, erythematous rash, urticaria, angio-oedema, vomiting, rhinorrhoea, and cough. Five infants were being followed prospectively and 4 were clinically tolerant of the food by age 16 months. The most likely route of sensitisation was via breast milk. None of the infants experienced similar reactions while being breast fed, suggesting that the reaction was dose dependent. As 5 out of a group of 80 infants being followed prospectively developed an immediate reaction at their first known exposure to a food, this appeared to be a not uncommon presentation of food hypersensitivity in infancy.

Food hypersensitivity reactions may occur in infants, often in association with other atopic manifestations. ${ }^{12}$ The occurrence of hypersensitivity reactions to ingested substances requires exposure of the immune system to the relevant antigen with the production of IgE antibodies. If such reactions occur in infants without known prior exposure to the substance, presumably sensitisation has occurred either prenatally, or in the postnatal period inadvertently or through the breast milk. There have been several anecdotal reports of reactions occurring in infants upon the first known exposure to cows' milk ${ }^{13-6}$ and egg. ${ }^{7}$ However, it is possible that the food, particularly cows' milk, might have been given previously in the neonatal period. In addition many of the reactions were not typical of IgE-mediated hypersensitivity. In particular, the eczematous manifestations noted by Kuroume et $a l^{3}$ and Matsumara et al. ${ }^{7}$ often occurred days after the food had been ingested. Warner ${ }^{8}$ recently documented 2 infants who reacted to their first known exposure to food. However, eczema, which is not considered to be primarily IgE-mediated ${ }^{9}$ was the major manifestation, and in one child the reaction was delayed 24 hours. We wish to report 8 infants in whom immediate hypersensitivity-type reactions occurred at the first known exposure to a food.

CSL $=$ Commonwealth Serum Laboratories.

CSIRO $=$ Commenwealth Scientific and Industrial Research Organisation.

\section{Subjects and methods}

The first 5 infants formed part of a prospective study on 80 infants of atopic parents. All infants were seen initially in the neonatal period and were followed every 4 months until at least age 16 months. At each visit a careful history was obtained, noting particularly atopic symptoms and feeding history, and a physical examination and allergen skin prick tests were performed. The skin prick tests consisted of histamine $(1 \mathrm{mg} / \mathrm{ml})$, control (HollisterStier), whole cows' milk (Hollister Stier), egg albumen (CSL), wheat (CSIRO), and Dermatophagoides pteronyssinus (Bencard). Reactions were read after 10 minutes and the size of the weal and flare was recorded. The weal size was determined as the mean of the maximum and minimum diameters and only the weal sizes of symptomatic foods are reported.

Three (Cases 6, 7, and 8) infants presented to the allergy clinic at this hospital. All had clinical reactions to peanut and were skin-prick tested as described above using a commercial peanut extract (Hollister-Stier) and specially prepared raw, roast, and purified peanut extracts. The infants were also tested with a variety of other allergens including whole egg (Hollister-Stier), egg white (CSL), cows' milk, pea, and yeast (Hollister-Stier), D. pteronyssinus (Dome), cat fur, and rye grass (HollisterStier). 
Table Nature of food hypersensitivity reactions

\begin{tabular}{|c|c|c|c|c|c|c|}
\hline Case & Food & $\begin{array}{l}\text { Age at reaction } \\
\text { (months) }\end{array}$ & Symptoms & $\begin{array}{l}\text { Onset } \\
(\mathrm{min})\end{array}$ & $\begin{array}{l}\text { No of times } \\
\text { observed }\end{array}$ & $\begin{array}{l}\text { Maximum } \\
\text { weal size }(\mathrm{mm})\end{array}$ \\
\hline 1 & Egg & 5 & $\begin{array}{l}\text { Irritable, erythematous rash, rhinorrhoea, } \\
\text { watery eyes, angio-oedema eyelids }\end{array}$ & 10 & 4 & 3 \\
\hline \multirow[t]{2}{*}{2} & Milk & $3 \frac{1}{2}$ & $\begin{array}{l}\text { Angio-oedema lip and ears, erythematous } \\
\text { rash, vomiting }\end{array}$ & 5 & 4 & 1 \\
\hline & Egg & $3 \frac{1}{2}$ & $\begin{array}{l}\text { Angio-oedema lip and ears, erythematous } \\
\text { rash, vomiting }\end{array}$ & 5 & 6 & 6 \\
\hline 3 & Egg & $6 \frac{1}{2}$ & Screaming & 30 & 4 & 3 \\
\hline 4 & Milk & $2 \frac{1}{2}$ & Erythematous rash and vomiting & 60 & 2 & 2 \\
\hline 5 & Egg & 5 & Vomiting & 30 & 1 & 3 \\
\hline 6 & Peanut & 6 & Urticarial rash & 1 & 2 & 5 \\
\hline \multirow[t]{2}{*}{7} & Peanut & 2 & Angio-oedema lips and trunk & 5 & 1 & 7 \\
\hline & Egg & 8 & $\begin{array}{l}\text { Angio-oedema eyes, erythematous rash, } \\
\text { cough }\end{array}$ & 2 & 1 & 9 \\
\hline \multirow[t]{2}{*}{8} & Egg & 5 & Angio-oedema lips & 5 & 2 & 4 \\
\hline & Peanut & 12 & $\begin{array}{l}\text { Angio-oedema lips, urticaria of face and } \\
\text { neck }\end{array}$ & 5 & 2 & 5 \\
\hline
\end{tabular}

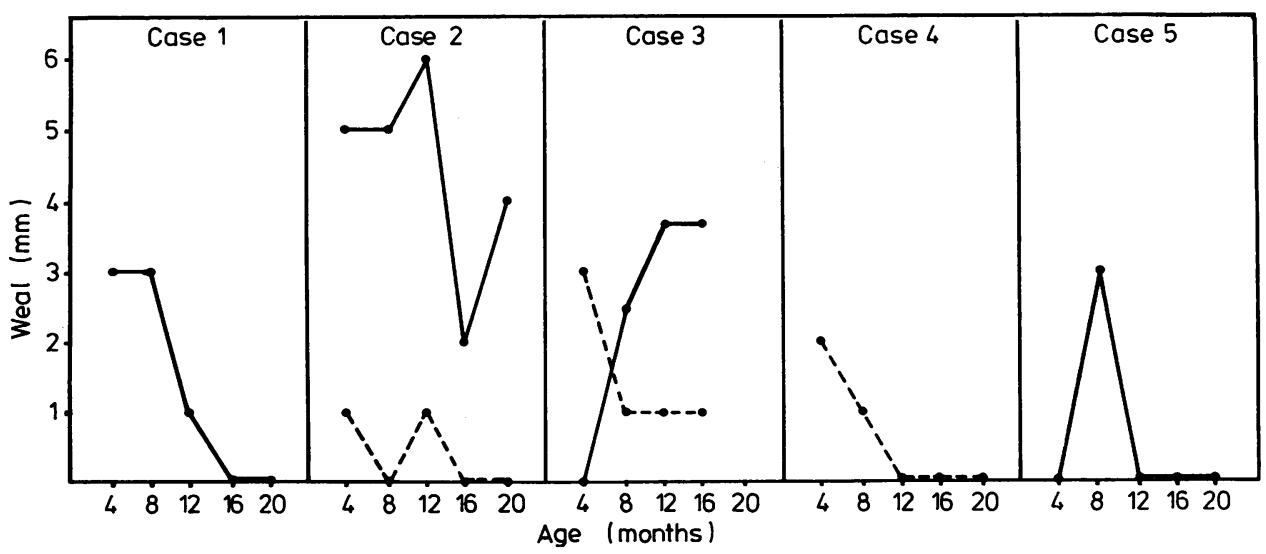

Figure Skin test results for the symptomatic foods in the prospectively studied infants (Cases 1-5). The allergens are egg albumen (continuous line) and whole cows' milk (dotted line).

\section{Results}

A summary of the clinical features of the food hypersensitivity reactions in the 8 infants appears in the Table. All infants were breast fed for periods ranging from 3 to 12 months and each one reacted to the particular food on his first known exposure to it. In the cases of milk sensitivity the reaction was to the first foreign protein received.

The skin test reactions to the symptomatic foods are illustrated for the prospectively-studied infants in the Figure. Two (Cases 1 and 3) infants were skin-test positive to the food before the exposure. All the prospectively-studied infants were tolerant of the food concerned by 16 months, apart from Case 3 who was still sensitive to egg.

\section{Discussion}

All 8 infants in this report developed symptoms of an immediate hypersensitivity reaction on their first known exposure to the particular food. Presumably their previous sensitisation must have occurred either in utero, through breast milk, by inadvertent administration of the food concerned, or perhaps (in Cases 3 and 5) through the skin tests. Although suspected in utero sensitisation has been reported ${ }^{3}{ }^{710}$, only Kaufman ${ }^{10}$ demonstrated an IgE-mediated reaction. It also seems that in utero sensitisation is rare. Kjellman and Johannson ${ }^{11}$ found no positive reaction to radioallergosorbent test in 99 analyses of cord blood, although Michel et al. ${ }^{12}$ demonstrated the presence of cows' milk specific IgE in the cord blood of only 3 of 136 newborn infants. It is not clear whether these infants had reactions on their first known exposure to milk. In Cases 3 and 5 skin tests to egg albumen were negative at 4 months but positive at 8 months, suggesting that specific IgE antibodies had developed 
after 4 months. Inadvertent administration of foods is more likely with cows' milk and egg, the former particularly during the neonatal period. However, all infants with milk or egg sensitivity had been followed up prospectively since the neonatal period and feeding history had been carefully documented, particularly in regard to cows' milk supplementation. In the case of peanuts, it has been shown recently that although the peanut proteins themselves are allergenic, peanut oil, which might be given inadvertently, is non-allergenic. ${ }^{13}$ It is most unlikely that the peanut-sensitive patients could be given peanut products unknown to the mother. Two infants developed reactions after initial negative skin tests although it seems unlikely that enough antigen would be introduced to sensitise these infants. Furthermore, all the infants followed prospectively were skin tested routinely every 4 months and 4 of 5 became negative to at least one food antigen, suggesting that skin tests were not the cause of sensitisation. We believe the most likely route of sensitisation was exposure to the food allergens through maternal breast milk.

The presence of food antigens in breast milk was described in 1930, ${ }^{14}$ and reconfirmed in recent reports both indirectly via skin tests using maternal breast milk ${ }^{6} 8$ and by direct demonstration of food antigens using specific rabbit anti-sera. ${ }^{15}{ }^{16}$ It appears that breast feeding may enhance both total ${ }^{17} 18$ and specific $^{17-19}$ IgE production. Jarrett's hypothesis ${ }^{20}$ provides an explanation for these findings. She proposed that small doses of antigen might stimulate helper T-cells and thus promote IgE production, whereas large doses of antigen stimulate suppressor T-cells, inhibiting IgE production. Our observations are consistent with this. IgE production was shown by positive skin tests in fully breast-fed infants, in whom the antigen dose is likely to be low, and the skin tests decreased in size or became negative when clinical tolerance was achieved.

Several authors have suggested that food allergens, particularly cows' milk, might produce symptoms in infants by passage through maternal breast milk.1378152122 The clinical histories of our patients do not support this proposition. None of our infants, while breast fed, had a reaction similar to that encountered on first exposure to the food allergen. Although 3 of the infants had 'colic' (Cases 1, 2, and 8), this was generally intermittent and the duration of symptoms much shorter than the period of breast feeding. In addition none of the infants reported 'colic' as a symptom associated with the adverse reaction to the food concerned. Several infants also developed atopic manifestations while being breast fed, but again exposure to the food did not cause an exacerbation of these problems. The dose of allergen in the breast milk if enough to cause sensitisation, was obviously not sufficient to cause symptoms of immediate hypersensitivity.

It was of interest that 4 out of 5 of the patients followed prospectively became tolerant of the food concerned by age 16 months. This finding has been well documented with cows' milk protein allergen ${ }^{51}$ and more recently was reported for soy, egg, and peanut. ${ }^{23}$ Tolerance was more likely to develop with milk and egg than with peanut, supporting Bock's findings. ${ }^{23}$ In fact none of our peanutsensitive patients was shown to tolerate peanut. The skin test responses to the food reflected the clinical sensitivity and in 4 of the 5 prospectively-studied infants, skin tests have become negative after tolerance was achieved (Figure).

We have described 8 infants, each with an immediate hypersensitivity reaction to a food on the first known exposure, with the most likely route of sensitisation before maternal breast milk. Each had a reaction starting within the first hour of exposure and lasting only 1-2 hours, and all had positive allergen skin prick tests to the appropriate food, suggesting IgE mediation of the reaction. The identification of 5 cases in 80 prospectivelystudied infants of atopic parents indicates that this is not an uncommon manifestation of food hypersensitivity reactions in infancy.

We thank Dr $\mathbf{R}$ Kamath and Dr $\mathbf{S}$ Towns for reviewing the manuscript, Ms $S$ Morvan for secretarial assistance, and all parents who participated in the prospective study.

P P V A was supported by a National Health and Medical Research Council Fellowship in Allergic Diseases.

\section{References}

1 Bock S A, Lee W Y, Remigo L K, May C D. Studies of hypersensitivity reactions to foods in infants and children.J Allergy Clin Immunol 1978; 62 : 327-34.

2 Ford R P K, Fergusson D M. Egg and cows' milk allergy in children. Arch Dis Child 1980; 55 : 608-10.

3 Kuroume T, Oguri M, Matsumara T, et al. Milk sensitivity and soybean sensitivity in the production of eczematous manifestations in breast fed infants with particular reference to intra-uterine sensitization. Ann Allergy1976; 37: 41-6.

4 Fällström S P, Ahlstedt S, Hanson L A. Specific antibodies in infants with gastrointestinal intolerance to cows' milk protein. Int Arch Allergy Appl Immunol 1978; 56: 97-105.

5 Hill D J, Davidson G P, Cameron D J, Barnes G L. The spectrum of cows' milk allergy in childhood. Acta Paediatr Scand 1979; 68: 847-52.

6 Jakobsson I, Lindberg T. A prospective study of cows' milk protein intolerance in Swedish infants. Acta Paediatr Scand 1979; 68: 853-9. 
7 Matsumura T, Kuroume T, Oguri M, et al. Egg sensitivity and eczematous manifestations in breast-fed newborns with particular reference to intrauterine senzitisation. Ann Allergy 1975; 35 : 221-9.

8 Warner $J$ O. Food allergy in fully breast-fed infants. Clin Allergy 1980; 10: 133-6.

9 Atherton D J. Allergy and atopic eczema I. Clin Exp Dermatol 1981; 6: 191-203.

10 Kaufman H S. Allergy in the newborn: skin test reactions confirmed by the Prausnitz-Kustner test at birth. Clin Allergy 1971; 1: 363-7.

11 Kjellman N I M, Johansson S G O. IgE and atopic allergy in newborns and infants with a family history of atopic disease. Acta Paediatr Scand 1976; 65: 601-7.

12 Michel F B, Bousquet J, Greillier P, Robinet-Levy M, Coulomb Y. Comparison of cord blood immunoglobulin E concentrations and maternal allergy for the prediction of atopic diseases in infancy. $J$ Allergy Clin Immunol $1980 ; 65$ : 422-30.

13 Nordlee J A, Taylor S L, Jones R T, Yunginger J W. Allergenicity of various peanut products as determined by RAST inhibition. J Allergy Clin Immunol 1981; 68: 376-82.

14 Donnally $\mathrm{H} \mathrm{H}$. The question of the elimination of foreign protein (egg white) in woman's milk. J Immunol 1930; 19: 15-40.

15 Jakobsson I, Linberg T. Cows' milk as a cause of infantile colic in breast-fed infants. Lancet 1978; ii: 437-9.
16 Hemmings W A, Kulangara A C. Letter: Dietary antigens in breast milk. Lancet 1978; ii: 575.

17 Björkstén F, Saarinen U M. Letter: IgE antibodies to cows' milk in infants fed breast milk and milk formulae. Lancet 1978; ii : 624-5.

18 Juto P, Bjorkstein B. Serum IgE in infants and influence of type of feeding. Clin Allergy 1980; 10: 593-600.

19 Kaplan M S, Solli N J. Immunoglobulin E to cows' milk protein in breast-fed atopic children. $J$ Allergy Clin Immunol 1979; 64: 122-6.

20 Jarrett E E E. Activation of IgE regulatory mechanisms by transmucosal absorption of antigen. Lancet 1977; ii : $223-5$.

21 Dannaeus A, Johansson S G O. A follow-up study of infants with adverse reactions to cows' milk. I. Serum IgE, skin test reactions, and RAST in relation to clinical course. Acta Paediatr Scand 1979; 68: 377-82.

22 Gerrard J W. Allergy in breast-fed babies to ingredients in breast milk. Ann Allergy 1979; 42: 69-72.

23 Bock S A. The natural history of food sensitivity. $J$ Allergy Clin Immunol 1982; 69: 173-7.

Correspondence to Dr A S Kemp, Department of Immunology, Royal Alexandra Hospital for Children, PO Box 31, Camperdown, New South Wales 2050, Australia.

Received 23 December 1982 